\title{
Alelopatia de Plantas de Cobertura na Superfície ou INCORPORADAS AO SOlO NO CONTROLE DE Digitaria spp. ${ }^{1}$
}

\author{
Allelopathy of Cover Crops on the Soil Surface or Incorporated into the Soil for Digitaria spp. \\ Control \\ MORAES, P.V.D. ${ }^{2}$, AGOSTINETTO, D. ${ }^{3}$, PANOZZO, L.E. ${ }^{4}$, TIRONI, S.P. ${ }^{5}$, GALON, L. ${ }^{6}$ e \\ SANTOS, L.S. ${ }^{5}$
}

\begin{abstract}
RESUMO - Os aleloquímicos podem sofrer modificações em diversos tipos de substrato, tanto incorporados quanto na superfície do solo. O objetivo deste estudo foi investigar os efeitos de diferentes niveis de palha de culturas de cobertura, quando incorporadas ou mantidas na superficie do solo, sobre a emergência e o desenvolvimento inicial de Digitaria spp. (milhã, capim-colchão e capim-de-roça). O delineamento experimental utilizado foi em bloco ao acaso, com quatro repetições. Os tratamentos foram arranjados em esquema fatorial com os seguintes fatores: (A) - manejo das coberturas (incorporado e na superficie do solo); (B) culturas de cobertura de solo (canola, nabo forrageiro, trevo-vesiculoso e azevém); e (C) niveis de palha $\left(0,1,2,4,6\right.$ e $\left.10 \mathrm{tha}^{-1}\right)$. Com o aumento dos niveis de palha de canola e nabo forrageiro incorporados ao solo, há em geral aumento na redução das variáveis IVE e porcentagem de emergência de milhã. A presença de palha de azevém na superficie do solo reduz o crescimento de milhã, comparativamente à incorporação, sendo necessário ao menos $6 \mathrm{t} \mathrm{ha}^{-1}$ de palha.
\end{abstract}

Palavras-chave: Lolium multiflorum, Raphanus sativus, Trifolium vesiculosum, Brassica napus, aleloquímicos.

\begin{abstract}
Allelochemicals can undergo changes in cover crops maintained on the soil surface or incorporated into soil. The objective of this study was to investigate the effect of different levels of cover crop straw, incorporated or not into soil, on the emergence and initial development of crabgrass (Digitaria spp.). The experiment was arranged in a randomized complete block design with 4 replications and treatments were arranged in a factorial scheme where: A)- management of cover crops (incorporated or not into the soil); B) - cover crops (Brassica napus, Raphanus sativus, Trifolium vesiculosum and Lolium multiflorum) and $C$ ) - straw levels (O, 1, 2, 4, 6 and $10 \mathrm{t} \mathrm{h \textrm {A } ^ { - 1 }}$ ). Increased straw levels of Brassica napus and Raphanus sativus incorporated into the soil leads to an increase in the reduction of the variables IVE and percentage of Digitaria spp. emergence. The presence of Lolium multiflorum straw on the soil surface reduces the growth of Digitaria spp., compared to incorporation into the soil, with at least $6 t$ ha ${ }^{-1}$ of straw being necessary.
\end{abstract}

Keywords: Lolium multiflorum, Raphanus sativus, Trifolium vesiculosum, Brassica napus, allelochemicals.

\section{INTRODUÇÃO}

O gênero Digitaria spp. (milhã, capimcolchão, capim-de-roça) ocorre frequentemente em ambientes produtivos e apresenta plantas altamente agressivas com elevada adaptabilidade ecológica, constituindo-se em sério problema para culturas de primavera e verão (Barberi et al., 1998; López-Ovejero et al., 2007). Preferem solos bem trabalhados e

Recebido para publicação em 4.8.2010 e aprovado em 10.3.2011.

2 Engô-Agr ${ }^{0}$., Dr., Pós-Doutorando - Plant and Soil Sciences, University of Kentucky/Lexington/KY/USA, <pvdmoraes@gmail.com>;

${ }^{3}$ Engo-Agr ${ }^{\circ}$, Dr., Professor da Faculdade de Agronomia Eliseu Maciel, FAEM/UFPEL, Bolsista do CNPq; ${ }^{4}$ Engo-Agro ${ }^{\circ}$, M.Sc., Aluno do Programa de Pós-Graduação em Fitotecnia, Universidade Federal de Viçosa - DFT/UFV; ${ }^{5}$ Alunos do Curso de Agronomia, FAEM/UFPel; ${ }^{6}$ Eng$^{\circ}$-Agr ${ }^{\circ}$., Dr., Prof. da Universidade Federal do Pampa - UNIPAMPA, Campus Itaqui-RS 
férteis, mas ocorrem também em solos mais compactados e pobres. Dessa forma, práticas de manejo com mínimo impacto ambiental e que reduzam o efeito negativo da planta daninha sobre as culturas podem ser necessárias para evitar perdas na produtividade.

Uma dessas práticas de manejo é o controle de plantas daninhas pela atividade alelopática das plantas de cobertura, em semeadura direta ou incorporação destas em sistema convencional. Entretanto, isso depende diretamente da qualidade e quantidade do material depositado, do tipo de solo, da população microbiana, das condições climáticas e da composição de espécies da comunidade de plantas daninhas de forma específica (Monquero et al., 2009). A escolha adequada da espécie, associada ao manejo da cobertura em pré-semeadura da cultura, também pode ser importante para intensificar o efeito alelopático sobre as plantas daninhas (Moraes et al., 2009), visto que em quantidades similares de palha poderá haver respostas distintas entre as coberturas para uma mesma espécie de planta daninha (Correia et al., 2006).

A decomposição de resíduos vegetais é a principal fonte de liberação dos aleloquímicos no solo. Durante o processo de decomposição microbiana ocorre a perda da integridade da membrana celular, o que permite a liberação de grande número de compostos que impõem toxicidade às plantas vizinhas (MaraschinSilva \& Áquila, 2006).

Os aleloquímicos podem sofrer modificações em função da cobertura a ser incorporada ou mantida na superficie do solo (Ferreira \& Áquila, 2000). O manejo adequado da cobertura vegetal é importante tanto em semeadura direta como em plantio convencional para controle de plantas daninhas. A decomposição do material sobre o solo é mais lenta, o que pode afetar o nivel da concentração de aleloquímicos no solo; contudo, se o nível crítico de concentração de aleloquímicos for atingido, a decomposição lenta seria vantajosa, pelo maior período de ação alelopática (Rezende et al., 2003).

A decomposição da palha no solo libera gradativamente aleloquímicos, que podem interferir diretamente na germinação e emergência de plantas daninhas, afetando assim a viabilidade das sementes. Quando incorporados ao solo, os resíduos mostram-se tóxicos à emergência de plantas daninhas, em comparação com a cobertura mantida na superficie do solo (Medeiros \& Lucchesi, 1993; Mathiassen et al., 2006).

O objetivo deste trabalho foi investigar os efeitos das culturas de cobertura, quando incorporadas ou mantidas na superficie do solo em diferentes níveis de palha, sobre a emergência e o desenvolvimento inicial de Digitaria spp.

\section{MATERIAL E MÉTODOS}

O experimento foi conduzido em casa de vegetação, sendo as plantas de coberturas semeadas em vasos com capacidade de oito litros. Para obtenção dos resíduos vegetais, elas foram coletadas em estádio de florescimento. As raizes das plantas, no momento da coleta, foram lavadas e posteriormente secas à sombra em temperatura ambiente, juntamente com a parte aérea. Depois, foi determinado o teor de umidade residual nos tecidos, pela secagem de amostras em estufa a $60^{\circ} \mathrm{C}$ por periodo de 120 horas, para se proceder à correção da umidade, tendo como base a matéria seca.

Os resíduos vegetais foram picados em segmentos de aproximadamente $1-1,5 \mathrm{~cm}$, e seu peso foi corrigido tendo como referência a base seca. A matéria seca foi ajustada conforme o volume de solo dos vasos, para posteriormente ser homogeneizada e incorporada ou mantida na superficie do solo, conforme os tratamentos.

O delineamento experimental utilizado foi em blocos ao acaso, com quatro repetições. Os tratamentos foram arranjados em esquema com três fatores, em que o fator A constou de manejo das coberturas (incorporado e na superficie do solo); o fator B constituiu-se de culturas de cobertura de solo: canola (Brassica napus), nabo forrageiro (Raphanus sativus), trevo-vesiculoso (Trifolium vesiculosum) e azevém (Lolium multiflorum); e o fator $\mathrm{C}$ foram os niveis de palha $\left(0,1,2,4,6\right.$ e $\left.10 \mathrm{t} \mathrm{ha}^{-1}\right)$.

Cada unidade experimental foi composta por vasos plásticos com capacidade para 800 gramas de solo, utilizando-se como substrato 
solo Argissolo Vermelho-Amarelo, de textura franco-arenosa (Embrapa, 2006). Aleatoriamente, foram semeadas 20 sementes em cada vaso, as quais foram cobertas com aproximadamente $1 \mathrm{~cm}$ de solo. A porcentagem média de emergência da planta daninha foi de $91,3 \%$, conforme mostra a Tabela 2. Neste estudo não foi realizada a identificação da espécie utilizada.A irrigação foi realizada diariamente, para manter o solo úmido.

Foi feita a contagem diária das plântulas emergidas por período de oito dias, para determinar o índice de velocidade de emergência (IVE). O IVE foi calculado pela fórmula descrita por Maguire (1962) e modificada por Wardle et al. (1991), sendo IVE $=[\mathrm{N} 1 /$ $1+\mathrm{N} 2 / 2+\mathrm{N} 3 / 3+\ldots . \mathrm{Nn} / \mathrm{n})]$, em que $\mathrm{N} 1$, N2, N3...Nn são o número de sementes emergidas, e 1, 2, 3..n, o número de dias após semeadura.

No final do período de avaliação do IVE, foi quantificada a porcentagem de emergência e, após, realizado desbaste, deixando quatro plantas por vaso. Aos 30 dias após emergência (DAE), foi realizada a quantificação das variáveis estatura da parte aérea (EST), área foliar (AF) e matéria seca da parte aérea (MSPA) e de raízes (MSR).

A EST foi determinada pela medida do comprimento desde o nivel do solo até o ápice. A AF foi determinada com auxílio de medidor de AF (modelo Licor $3100 C$ ). As raízes e a parte aérea foram separadas. As raízes foram lavadas com água para retirada do solo, sendo o material coletado (parte aérea e raízes) seco em estufa à temperatura de $60{ }^{\circ} \mathrm{C}$ até atingir massa constante.

Os valores de emergência, após avaliação de homocedasticidade, foram transformados por arco-seno $\sqrt{ } \mathrm{x} / 100$. Os dados obtidos foram submetidos à análise de variância pelo teste F e, em caso de se constatar significância estatística, procedeu-se à comparação entre médias para o fator incorporação pelo teste $t$ $(p \leq 0,05)$. Para o fator culturas de cobertura, utilizou-se o teste de Tukey $(\mathrm{p} \leq 0,05)$, e para o fator niveis de palha, foram utilizados modelos lineares de regressão (equações quadráticas) $(\mathrm{p} \leq 0,05)$.

\section{RESULTADOS E DISCUSSÃO}

Os fatores estudados apresentaram interação para a variável índice de velocidade de emergência (IVE) de milhã (Digitaria spp.). Quando as coberturas não foram incorporadas ao solo, houve em geral aumento no IVE, comparativamente à incorporação. Do total de comparações realizadas, excluindo as testemunhas, verificou-se que em $75 \%$ das comparações houve diferença; para canola, nabo forrageiro e azevém, a incorporação reduziu, em geral, o IVE, enquanto para o trevo-vesiculoso observou-se aumento (Tabela 1).

A liberação de aleloquímicos na superficie do solo através da decomposição é mais lenta (Rezende et al., 2003), não interferindo no processo germinativo a curto prazo, como ocorreu neste estudo.

Tabela 1 - Índice de velocidade de emergência de Digitaria spp. (milhã), em função de manejo, espécies e níveis de palha de culturas utilizadas como cobertura de solo

\begin{tabular}{|c|c|c|c|c|c|c|c|c|}
\hline \multirow{2}{*}{$\begin{array}{c}\text { Nível de } \\
\text { palha } \\
\left(\mathrm{t} \mathrm{ha}^{-1}\right)\end{array}$} & \multicolumn{4}{|c|}{ Sem incorporação } & \multicolumn{4}{|c|}{ Com incorporação } \\
\hline & Canola & $\begin{array}{c}\text { Nabo } \\
\text { forrageiro }\end{array}$ & $\begin{array}{c}\text { Trevo- } \\
\text { vesiculoso }\end{array}$ & Azevém & Canola & $\begin{array}{c}\text { Nabo } \\
\text { forrageiro }\end{array}$ & $\begin{array}{c}\text { Trevo- } \\
\text { vesiculoso }\end{array}$ & Azevém \\
\hline 0 & $23,2 \mathrm{a}^{1 / \mathrm{ns}}$ & $23,2 \mathrm{a}^{\mathrm{ns}}$ & $23,2 \mathrm{a}^{\mathrm{ns}}$ & $23,2 a^{n s}$ & $23,2 \mathrm{a}$ & $23,2 \mathrm{a}$ & $23,2 \mathrm{a}$ & $23,2 \mathrm{a}$ \\
\hline 1 & $12,8 \mathrm{~b}^{\mathrm{ns}}$ & $13,6 b^{\mathrm{ns}}$ & $19,0 b^{*}$ & $27,7 a^{*}$ & $17,6 \mathrm{c}$ & $15,9 \mathrm{c}$ & $28,8 \mathrm{~b}$ & $37,2 \mathrm{a}$ \\
\hline 2 & $23,7 b c *$ & $28,5 \mathrm{ab} *$ & $21,6 \mathrm{c}^{\mathrm{ns}}$ & $32,5 \mathrm{a}^{\mathrm{ns}}$ & $13,6 \mathrm{c}$ & $21,8 \mathrm{~b}$ & $22,5 \mathrm{~b}$ & $32,7 \mathrm{a}$ \\
\hline 4 & $32,7 \mathrm{ab} *$ & $26,5 \mathrm{bc} *$ & $22,9 \mathrm{c}^{*}$ & $33,5 a^{\mathrm{ns}}$ & $17,5 \mathrm{~b}$ & $15,7 \mathrm{~b}$ & $32,7 \mathrm{a}$ & $31,1 \mathrm{a}$ \\
\hline 6 & $30,9 \mathrm{a} *$ & $33,5 \mathrm{a} *$ & $31,8 a^{*}$ & $32,3 \mathrm{a} *$ & $9,7 \mathrm{~b}$ & $10,6 \mathrm{~b}$ & $38,6 \mathrm{a}$ & $14,4 \mathrm{~b}$ \\
\hline 10 & $33,9 \mathrm{a} *$ & $32,8 \mathrm{a} *$ & $38,6 \mathrm{a}^{*}$ & $22,1 \mathrm{~b} *$ & $4,5 \mathrm{c}$ & $17,3 \mathrm{a}$ & $19,7 \mathrm{a}$ & $11,0 \mathrm{~b}$ \\
\hline
\end{tabular}

${ }_{1}^{1}$ Médias seguidas por mesma letra minúscula na linha analisam culturas dentro de manejos da cobertura no solo e não diferem pelo teste de Tukey $(\mathrm{p} \leq 0,05) ;{ }^{n} \mathrm{e} *$ diferença não significativa e significativa, respectivamente, pelo teste $\mathrm{t}(\mathrm{p} \leq 0,05)$, para cada cultura entre os manejos. 
Contudo, quando comparadas as culturas de cobertura dentro do fator sem incorporação ao solo, verificou-se que todos os níveis de palha de azevém apresentaram maior IVE de milhã, com exceção do maior nível de palha, em que houve redução do IVE, diferindo das demais culturas de cobertura. A comparação entre culturas de cobertura, quando houve incorporação, demonstrou que a canola apresentou maior redução no IVE de milhã, correspondendo à redução média, em relação à testemunha, de $80 \%$ no maior nivel de palha, comparativamente a 25,15 e $52 \%$ de redução do IVE pela cobertura de nabo forrageiro, trevo-vesiculoso e azevém, respectivamente (Tabela 1).

Resultados contrários com soja foram encontrados por Maciel et al. (2003), em que o IVE foi reduzido pela palha de capim-braquiária na superficie do solo, ao passo que a incorporação da palha mostrou tendência a aumentar o IVE.

Os niveis de palha das culturas de cobertura, para a variável IVE de milhã, não demonstraram bom ajuste dos dados ao modelo (Figura 1). Houve ajuste dos dados do IVE ao modelo para trevo-vesiculoso e azevém, quando na superfície do solo ou incorporados ao solo.

A cobertura de trevo-vesiculoso na superficie do solo promoveu aumento no IVE. Para azevém, ocorreu a redução do IVE de milhã no maior nivel de palha $\left(10 \mathrm{t} \mathrm{ha}^{-1}\right)$. Quanto às espécies canola e nabo forrageiro, quando a cobertura foi mantida na superficie do solo, não houve ajuste dos dados ao modelo (Figura 1).

Quando a cobertura de trevo-vesiculoso foi incorporada ao solo, houve redução dessa variável no maior nivel de palha $\left(10 \mathrm{t} \mathrm{ha}^{-1}\right)$. Ocorreu redução do IVE de milhã com o aumento do nivel de palha de azevém incorporada ao solo (Figura 1).

A vantagem no atraso na emergência das plantas daninhas seria o aumento do período de tempo para realização do controle adequado, o que tornaria mais eficiente a operação em condições de campo. Em se tratando da variável porcentagem de emergência de milhã, os fatores testados apresentaram interação. As coberturas, quando não incorporadas, de modo geral, não diferiram, quando comparada à incorporação. Do total de comparações realizadas, excluindo as testemunhas, verificou-se que $55 \%$ não diferiram, em função da espécie e do manejo da cobertura do solo (Tabela 2).

A comparação entre as culturas de cobertura para o fator sem incorporação ao solo mostrou que elas não diferiram para a variável emergência, com exceção do menor nível de palha de canola e trevo-vesiculoso. Quando realizada a incorporação, houve redução significativa da emergência de milhã no maior

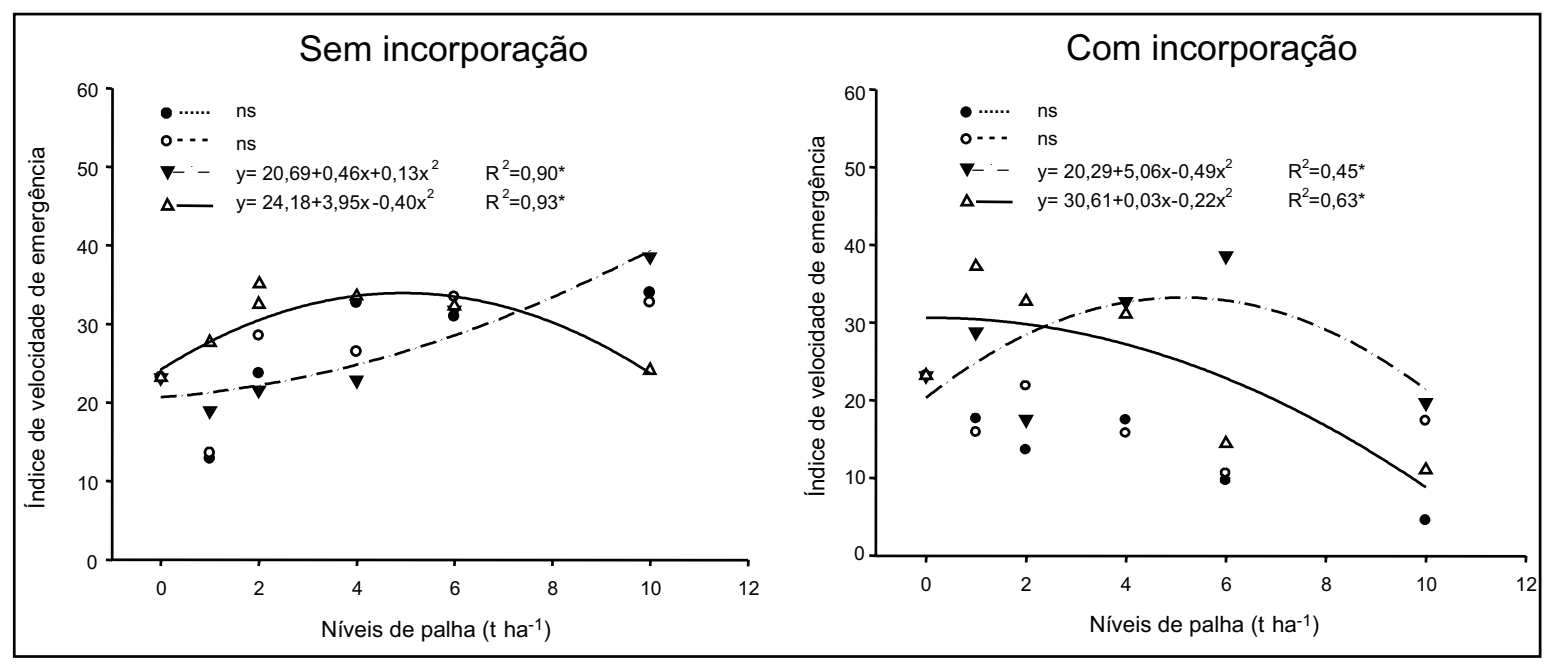

Figura 1 - Efeito de manejo, espécies e níveis de palha de culturas utilizadas como cobertura de solo no índice de velocidade de emergência de Digitaria spp. (milhã). ( $\bullet$ canola; o nabo forrageiro; $\boldsymbol{\nabla}$ trevo-vesiculoso; e $\Delta$ azevém). R²: coeficiente de determinação; ${ }^{\text {ns }} \mathrm{e}^{*}$ não significativo e significativo, respectivamente $(\mathrm{p} \leq 0,05)$. 
nivel de palha de nabo forrageiro e trevovesiculoso, em comparação com a cobertura de azevém (Tabela 2).

Resíduos de trevo-vermelho, quando incorporados ao solo rapidamente, liberam aleloquímicos, e a maior concentração se encontra na fase inicial de decomposição (Ohno et al., 2000). Em outro estudo, realizado por Monquero et al. (2009), verificou-se que grande quantidade de biomassa incorporada ao solo é capaz de reduzir a emergência de plantas de Ipomoea grandifolia, Brachiaria decumbens e Panicum maximum, independentemente das espécies de cobertura de solo.
Outro fato importante é que a cobertura de brássicas, quando incorporadas ou mantidas na superficie do solo, contém glucosinolatos, que podem afetar a germinação e reduzir o estabelecimento e crescimento de plantas daninhas (Norsworthy, 2003; Haramoto \& Gallandt, 2004), como foi verificado para o IVE e emergência no presente estudo.

Os niveis de palha das culturas de cobertura nos diferentes manejos, para a variávelresposta emergência de milhã, apresentaram ajuste dos dados ao modelo somente para canola não incorporada e nabo forrageiro incorporado ao solo (Figura 2).

Tabela 2 - Porcentagem de emergência de Digitaria spp. (milhã), em função de manejo, espécies e níveis de palha de culturas utilizadas como cobertura de solo

\begin{tabular}{|c|c|c|c|c|c|c|c|c|}
\hline \multirow{2}{*}{$\begin{array}{c}\text { Nível de } \\
\text { palha } \\
\left(\mathrm{t} \mathrm{ha}^{-1}\right)\end{array}$} & \multicolumn{4}{|c|}{ Sem incorporação } & \multicolumn{4}{|c|}{ Com incorporação } \\
\hline & Canola & $\begin{array}{c}\text { Nabo } \\
\text { forrageiro }\end{array}$ & $\begin{array}{c}\text { Trevo- } \\
\text { vesiculoso }\end{array}$ & Azevém & Canola & $\begin{array}{c}\text { Nabo } \\
\text { forrageiro }\end{array}$ & $\begin{array}{c}\text { Trevo- } \\
\text { vesiculoso }\end{array}$ & Azevém \\
\hline 0 & $91,3 \mathrm{a}^{1 / \mathrm{ns}}$ & $91,3 \mathrm{a}^{\mathrm{ns}}$ & $91,3 a^{n s}$ & $91,3 \mathrm{a}^{\mathrm{ns}}$ & $91,3 \mathrm{a}$ & $91,3 \mathrm{a}$ & $91,3 \mathrm{a}$ & $91,3 \mathrm{a}$ \\
\hline 1 & $65,0 b^{*}$ & $90,0 \mathrm{a}^{*}$ & $78,8 \mathrm{ab}^{*}$ & $87,5 \mathrm{a}^{\mathrm{ns}}$ & $81,3 \mathrm{bc}$ & $76,3 \mathrm{c}$ & $93,8 \mathrm{ab}$ & $98,8 \mathrm{a}$ \\
\hline 2 & $92,5 \mathrm{a}^{*}$ & $83,8 \mathrm{a}^{\mathrm{ns}}$ & $88,8 \mathrm{a} *$ & $96,3 \mathrm{a}^{\mathrm{ns}}$ & $76,3 \mathrm{bc}$ & $92,5 \mathrm{a}$ & $71,3 \mathrm{c}$ & $91,3 \mathrm{ab}$ \\
\hline 4 & $85,0 \mathrm{a}^{\mathrm{ns}}$ & $85,0 a^{n s}$ & $92,5 \mathrm{a}^{\mathrm{ns}}$ & $87,5 \mathrm{a}^{\mathrm{ns}}$ & $75,0 \mathrm{~b}$ & $92,5 \mathrm{a}$ & $97,5 \mathrm{a}$ & $88,8 \mathrm{ab}$ \\
\hline 6 & $85,0 a^{n s}$ & $100,0 \mathrm{a}^{\mathrm{ns}}$ & $96,3 \mathrm{a}^{\mathrm{ns}}$ & $92,5 \mathrm{a}^{\mathrm{ns}}$ & $75,0 \mathrm{~b}$ & $92,5 \mathrm{a}$ & $92,5 \mathrm{a}$ & $85,0 \mathrm{ab}$ \\
\hline 10 & $98,8 \mathrm{a} *$ & $92,5 \mathrm{a} *$ & $91,3 \mathrm{a} *$ & $86,3 \mathrm{a}^{\mathrm{ns}}$ & $72,5 \mathrm{ab}$ & $68,8 \mathrm{~b}$ & $68,8 \mathrm{~b}$ & $86,3 \mathrm{a}$ \\
\hline
\end{tabular}

1/ Médias seguidas por mesma letra minúscula na linha analisam culturas dentro de manejos da cobertura no solo e não diferem pelo teste de Tukey $(\mathrm{p} \leq 0,05)$; ${ }^{\text {ns }} \mathrm{e} *$ diferença não significativa e significativa, respectivamente, pelo teste $\mathrm{t}(\mathrm{p} \leq 0,05)$, para cada cultura entre os manejos.

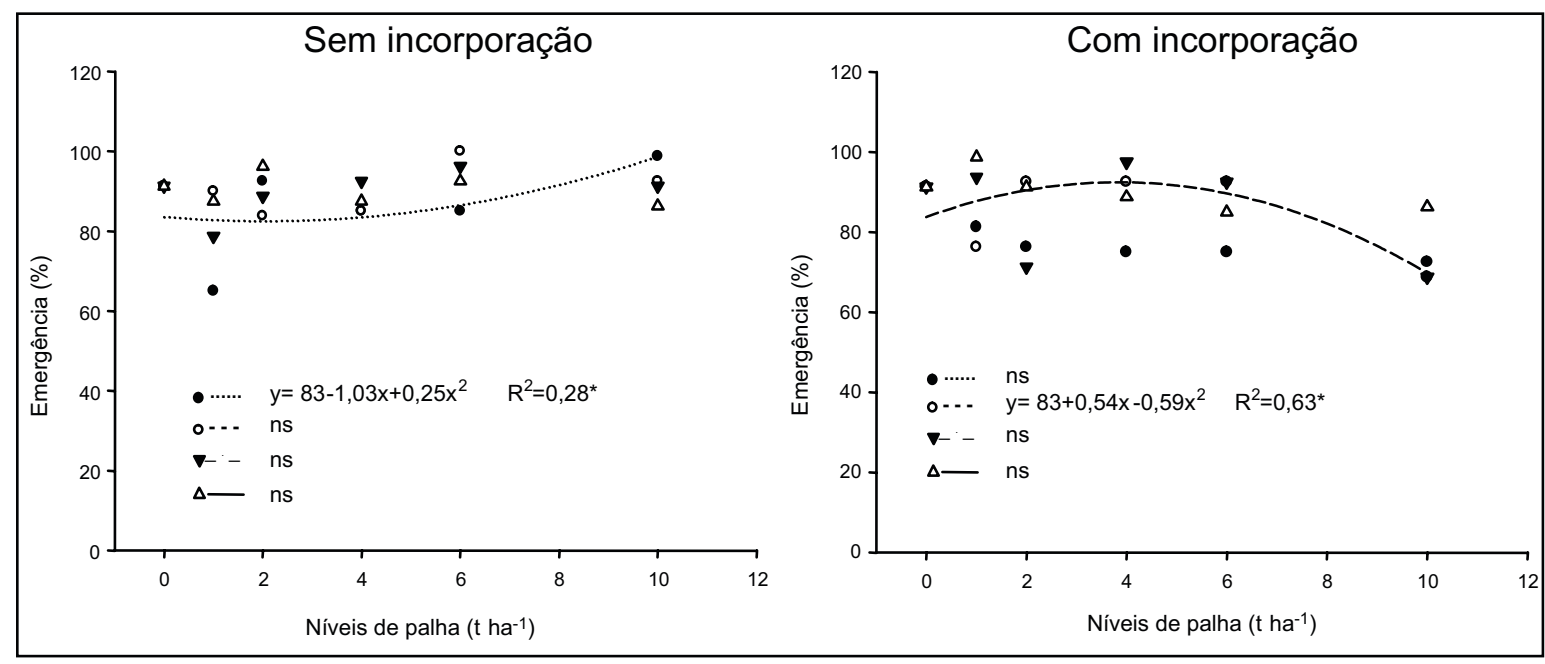

Figura 2 - Efeito de manejo, espécies e níveis de palha de culturas utilizadas como cobertura de solo na porcentagem de emergência de Digitaria spp. (milhã). ( $\bullet$ canola; o nabo forrageiro; $\boldsymbol{\nabla}$ trevo-vesiculoso; e $\Delta$ azevém). R²: coeficiente de determinação; ns $\mathrm{e}^{*}$ não significativo e significativo, respectivamente $(\mathrm{p} \leq 0,05)$. 
A cobertura de canola mantida na superfície do solo proporcionou maior porcentagem de emergência de milhã a partir de $2 \mathrm{t} \mathrm{ha}^{-1}$, ao passo que nabo forrageiro incorporado proporcionou redução da emergência dessa planta daninha a partir desse mesmo nivel de palha (Figura 2).

A incorporação da cobertura de brássicas e trevo-vesiculoso favoreceu a liberação de aleloquímicos no solo no curto período de avaliação, afetando a germinação. Sabe-se que espécies magnoliopsidas produzem coberturas de decomposição rápida, grande produção de matéria verde, baixa relação $\mathrm{C} / \mathrm{N}$, com ação alelopática intensa, mas de curta duração, o que pode ter influenciado a variável IVE e a emergência da planta daninha estudada neste trabalho.

Com a presença de palha sobre o solo, esperava-se maior redução da emergência, porém em alguns casos a palha pode favorecer a emergência de algumas espécies de plantas daninhas; isso ocorre, segundo Correia et al. (2006), devido à redução da amplitude térmica diária do solo, à conservação de umidade ou, ainda, a melhorias química, física e/ou biológica, fato observado para o IVE e a porcentagem de emergência de milhã.

Para a estatura (EST) de milhã, observouse interação entre os fatores manejo, culturas de cobertura e niveis de palha. Quando as coberturas não foram incorporadas ao solo, houve, em geral, redução da EST, quando comparadas às coberturas incorporadas ao solo. Para todas as comparações realizadas, excluindo as testemunhas, verificou-se que 95\% delas proporcionaram diferença em relação ao manejo da cobertura; para todas as culturas de cobertura, quando incorporadas ao solo, houve aumento na EST (Tabela 3).

Entretanto, quando comparadas as culturas de cobertura dentro do fator sem incorporação ao solo, os diferentes niveis de palha de canola pouco influenciaram na redução da EST de milhã, embora não tenham apresentado diferença das demais culturas de cobertura no maior nivel de palha. Quanto ao fator incorporação, as culturas de cobertura, quando comparadas, demonstraram que a cobertura de azevém apresentou tendência de redução na EST das plantas nos três maiores niveis de palha testados, quando comparada às demais culturas de cobertura, que proporcionaram aumento médio de $24 \%$ da EST de plantas, em relação à testemunha (Tabela 3 ).

Em estudos com manejo de palha de capim-braquiária (Brachiaria decumbens) na superficie ou incorporada ao solo, Maciel et al. (2003) verificaram que a estatura de plantas de soja e amendoim-bravo foi reduzida com a palha na superfície do solo. Já a incorporação de palha de trigo causa inibição ou estímulo do crescimento, dependendo da espécie de planta daninha (Mathiassen et al., 2006). A cobertura de azevém sobre o solo, em semeadura direta, pode proporcionar maior estatura da cultura do milho, quando comparada à cobertura de solo nabo forrageiro, trevo-vesiculoso e pousio (Moraes et al., 2009).

Os niveis de palha das culturas de cobertura, para a variável-resposta EST de plantas de milhã, demonstraram ajuste dos dados ao modelo quadrático somente para a cobertura de canola sem incorporação ou com incorporação e para nabo forrageiro quando incorporado. A cobertura com até $6 \mathrm{t}^{\mathrm{a}} \mathrm{a}^{-1}$ de palha de canola na superfície do solo proporcionou redução na EST, ao passo que a cobertura de canola e nabo forrageiro, quando incorporada, aumentou a EST de milhã, conforme aumento dos niveis de palha utilizados (Figura 3).

Observou-se interação entre os fatores testados para a variável área foliar (AF) de milhã. Quando a palha das culturas foi mantida na superficie do solo, houve, de modo geral, redução da $\mathrm{AF}$ de milhã, comparativamente à incorporação da palha ao solo. Do total de comparações realizadas, excluindo as testemunhas, verificou-se que $85 \%$ das comparações promoveram diferença para as culturas de cobertura; a partir de $2 \mathrm{t} \mathrm{ha}^{-1}$ de palha, houve diferença entre os manejos das coberturas (Tabela 4).

Quando comparadas as culturas de cobertura para o fator sem incorporação no solo, verificou-se que o azevém apresentou maior redução da $\mathrm{AF}$ de plantas de milhã no maior nível de palha, porém não diferiu da canola. Quando realizada a comparação das culturas de coberturas incorporadas ao solo, o azevém foi a cobertura que menos incrementou a $\mathrm{AF}$ de milhã, a partir de $4 \mathrm{t}$ ha ${ }^{1}$ de palha, seguido 
Tabela 3 - Estatura (cm) de plantas de Digitaria spp. (milhã), em função de manejo, espécies e níveis de palha de culturas utilizadas como cobertura de solo

\begin{tabular}{|c|c|c|c|c|c|c|c|c|}
\hline \multirow{2}{*}{$\begin{array}{c}\text { Nível de } \\
\text { palha } \\
\left(\mathrm{t} \mathrm{ha}^{-1}\right)\end{array}$} & \multicolumn{4}{|c|}{ Sem incorporação } & \multicolumn{4}{|c|}{ Com incorporação } \\
\hline & Canola & $\begin{array}{c}\text { Nabo } \\
\text { forrageiro }\end{array}$ & $\begin{array}{c}\text { Trevo- } \\
\text { vesiculoso }\end{array}$ & Azevém & Canola & $\begin{array}{c}\text { Nabo } \\
\text { forrageiro }\end{array}$ & $\begin{array}{c}\text { Trevo- } \\
\text { vesiculoso }\end{array}$ & Azevém \\
\hline 0 & $17,1 \mathrm{a}^{1 / \mathrm{ns}}$ & $17,1 \mathrm{a}^{\mathrm{ns}}$ & $17,1 \mathrm{a}^{\mathrm{ns}}$ & $17,1 \mathrm{a}^{\mathrm{ns}}$ & $17,1 \mathrm{a}$ & $17,1 \mathrm{a}$ & $17,1 \mathrm{a}$ & $17,1 \mathrm{a}$ \\
\hline 1 & $16,5 \mathrm{a}^{*}$ & $14,8 \mathrm{ab} *$ & $14,1 \mathrm{ab}^{\mathrm{ns}}$ & $13,6 b^{*}$ & $18,7 \mathrm{a}$ & $18,5 \mathrm{a}$ & $15,5 \mathrm{~b}$ & $16,4 \mathrm{ab}$ \\
\hline 2 & $15,8 a^{*}$ & $13,8 \mathrm{ab}^{*}$ & $12,6 b^{*}$ & $13,2 b^{*}$ & $18,0 \mathrm{a}$ & $17,5 \mathrm{a}$ & $17,0 \mathrm{a}$ & $15,5 \mathrm{a}$ \\
\hline 4 & $14,8 a^{*}$ & $14,9 \mathrm{a}^{*}$ & $12,7 a^{*}$ & $13,3 a^{*}$ & $20,6 \mathrm{a}$ & $20,5 \mathrm{a}$ & $22,7 \mathrm{a}$ & $16,7 \mathrm{~b}$ \\
\hline 6 & $15,4 \mathrm{a}^{*}$ & $14,3 \mathrm{ab}^{*}$ & $12,7 b^{*}$ & $12,8 \mathrm{ab}^{*}$ & $21,0 \mathrm{a}$ & $21,2 \mathrm{a}$ & $19,4 \mathrm{a}$ & $16,1 \mathrm{~b}$ \\
\hline 10 & $16,0 \mathrm{a}^{*}$ & $15,3 \mathrm{a}^{*}$ & $15,5 a^{*}$ & $13,7 a^{*}$ & $21,7 \mathrm{a}$ & $23,1 \mathrm{a}$ & $21,0 \mathrm{a}$ & $16,0 \mathrm{~b}$ \\
\hline
\end{tabular}

${ }^{1 /}$ Médias seguidas por mesma letra minúscula na linha analisam culturas dentro de manejos da cobertura no solo e não diferem pelo teste de Tukey $(\mathrm{p} \leq 0,05) ;{ }^{n}$ s $\mathrm{e}$ diferença não significativa e significativa, respectivamente, pelo teste $\mathrm{t}(\mathrm{p} \leq 0,05)$, para cada cultura entre os manejos.

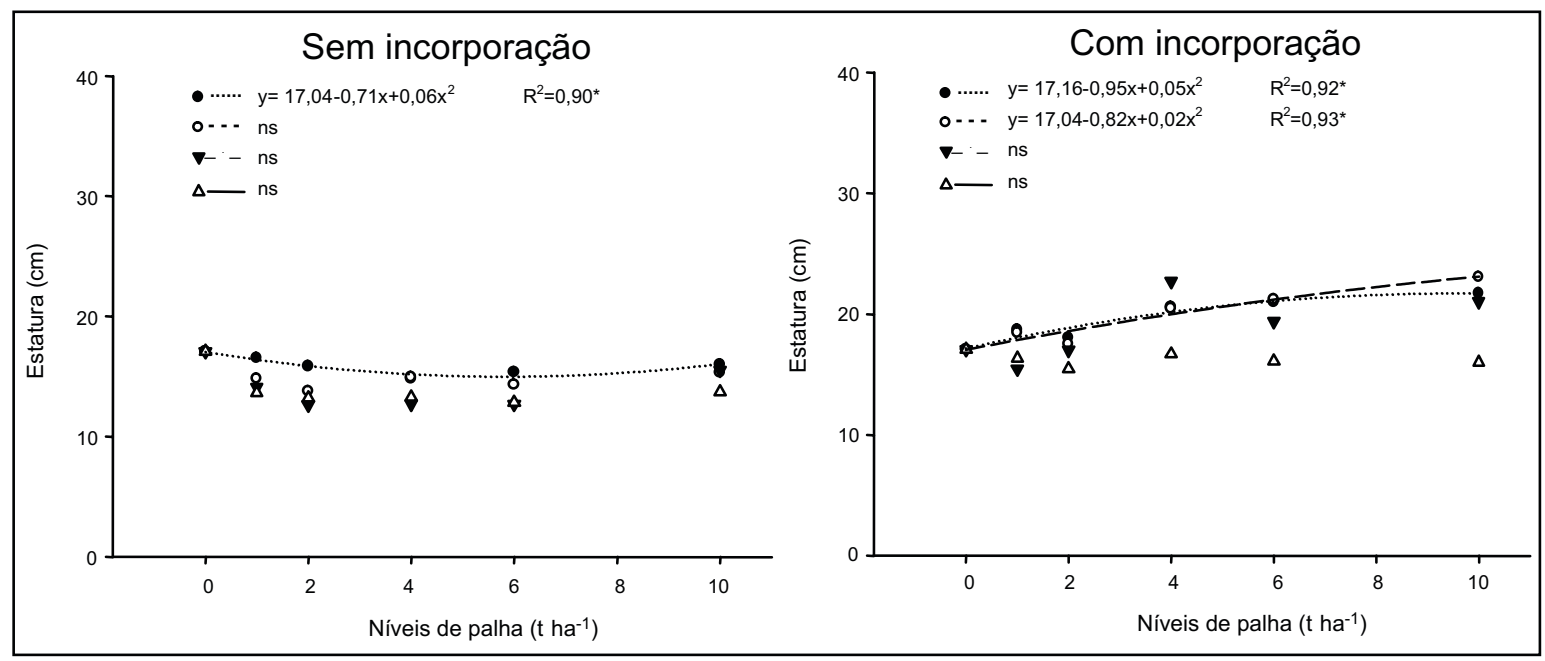

Figura 3 - Efeito de manejo, espécies e níveis de palha de culturas utilizadas como cobertura de solo na estatura de Digitaria spp. (milhã). ( $\bullet$ canola; o nabo forrageiro; $\boldsymbol{\nabla}$ trevo-vesiculoso; e $\Delta$ azevém). $\mathrm{R}^{2}$ : coeficiente de determinação, ${ }^{\text {ns }} \mathrm{e}^{*}$ não significativo e significativo, respectivamente $(\mathrm{p} \leq 0,05)$.

de trevo-vesiculoso a partir de $6 \mathrm{t}$ ha ${ }^{1}$ de palha (Tabela 4).

Neste estudo, pode-se verificar que a área foliar de milhã foi reduzida quando a palha foi mantida sobre o solo. Entretanto, Moraes et al. (2009), estudando diferentes culturas de cobertura para a cultura do milho, observaram que a cobertura morta de azevém sobre o solo pode proporcionar maior $\mathrm{AF}$ para a cultura do milho e menor número de plantas daninhas. Em outro estudo, Maciel et al. (2003) verificaram redução da área foliar de leiteiro quando a palha de capim-braquiária foi mantida na superficie do solo, comparativamente à incorporação.
Os niveis de palha das culturas de cobertura, para a variável-resposta $\mathrm{AF}$ de plantas de milhã, não demonstraram bom ajuste dos dados ao modelo. Quando mantida a cobertura na superfície do solo, a $\mathrm{AF}$ de milhã não se ajustou ao modelo, para nenhuma das culturas de cobertura. Entretanto, quando os diferentes níveis de palha foram incorporados ao solo, ocorreu aumento na AF das plantas de milhã que cresceram junto à cobertura de nabo forrageiro (Figura 4).

Os fatores testados apresentaram interação para a variável matéria seca da parte aérea (MSPA) de milhã. Quando as coberturas não foram incorporadas ao solo, houve, de modo 
Tabela 4 - Área foliar $\left(\mathrm{cm}^{2}\right)$ de plantas de Digitaria spp. (milhã), em função de manejo, espécies e níveis de palha de culturas utilizadas como cobertura de solo

\begin{tabular}{|c|c|c|c|c|c|c|c|c|}
\hline \multirow{2}{*}{$\begin{array}{l}\text { Nível de } \\
\text { palha } \\
\left(\mathrm{t} \mathrm{ha}^{-1}\right)\end{array}$} & \multicolumn{4}{|c|}{ Sem incorporação } & \multicolumn{4}{|c|}{ Com incorporação } \\
\hline & Canola & $\begin{array}{c}\text { Nabo } \\
\text { forrageiro }\end{array}$ & $\begin{array}{c}\text { Trevo- } \\
\text { vesiculoso }\end{array}$ & Azevém & Canola & $\begin{array}{c}\text { Nabo } \\
\text { forrageiro }\end{array}$ & $\begin{array}{c}\text { Trevo- } \\
\text { vesiculoso }\end{array}$ & Azevém \\
\hline 0 & $35,7 \mathrm{a}^{1 / \mathrm{ns}}$ & $35,7 \mathrm{a}^{\mathrm{ns}}$ & $35,7 \mathrm{a}^{\mathrm{ns}}$ & $35,7 \mathrm{a}^{\mathrm{ns}}$ & $35,7 \mathrm{a}$ & $35,7 \mathrm{a}$ & $35,7 \mathrm{a}$ & $35,7 \mathrm{a}$ \\
\hline 1 & $22,9 a b *$ & $28,6 a^{\mathrm{ns}}$ & $20,4 b^{\mathrm{ns}}$ & $23,6 \mathrm{ab}^{\mathrm{ns}}$ & $31,7 \mathrm{a}$ & $30,9 \mathrm{a}$ & $32,0 \mathrm{a}$ & $25,8 \mathrm{a}$ \\
\hline 2 & $29,8 \mathrm{a} *$ & $27,2 \mathrm{a} *$ & $20,7 \mathrm{a} *$ & $22,7 \mathrm{a} *$ & $41,3 \mathrm{a}$ & $38,8 \mathrm{ab}$ & $34,6 \mathrm{ab}$ & $32,3 \mathrm{~b}$ \\
\hline 4 & $27,1 \mathrm{a} *$ & $28,7 \mathrm{a} *$ & $23,7 \mathrm{a} *$ & $23,0 \mathrm{a} *$ & $44,6 \mathrm{a}$ & $46,3 \mathrm{a}$ & $48,0 \mathrm{a}$ & $33,2 \mathrm{~b}$ \\
\hline 6 & $30,6 \mathrm{a} *$ & $24,4 a b *$ & $21,5 \mathrm{~b} *$ & $21,1 \mathrm{~b} *$ & $44,4 \mathrm{~b}$ & $52,7 \mathrm{a}$ & $35,0 \mathrm{c}$ & $33,5 \mathrm{c}$ \\
\hline 10 & $26,1 \mathrm{ab} *$ & $28,9 \mathrm{a} *$ & $29,8 \mathrm{a} *$ & $20,3 \mathrm{~b} *$ & $51,6 \mathrm{~b}$ & $68,6 \mathrm{a}$ & $44,1 \mathrm{c}$ & $38,5 \mathrm{c}$ \\
\hline
\end{tabular}

1/Médias seguidas por mesma letra minúscula na linha analisam culturas dentro de manejos da cobertura no solo e não diferem pelo teste de Tukey $(\mathrm{p} \leq 0,05) ;{ }^{n} \mathrm{e}^{*}$ diferença não significativa e significativa, respectivamente, pelo teste $\mathrm{t}(\mathrm{p} \leq 0,05)$, para cada cultura entre os manejos.

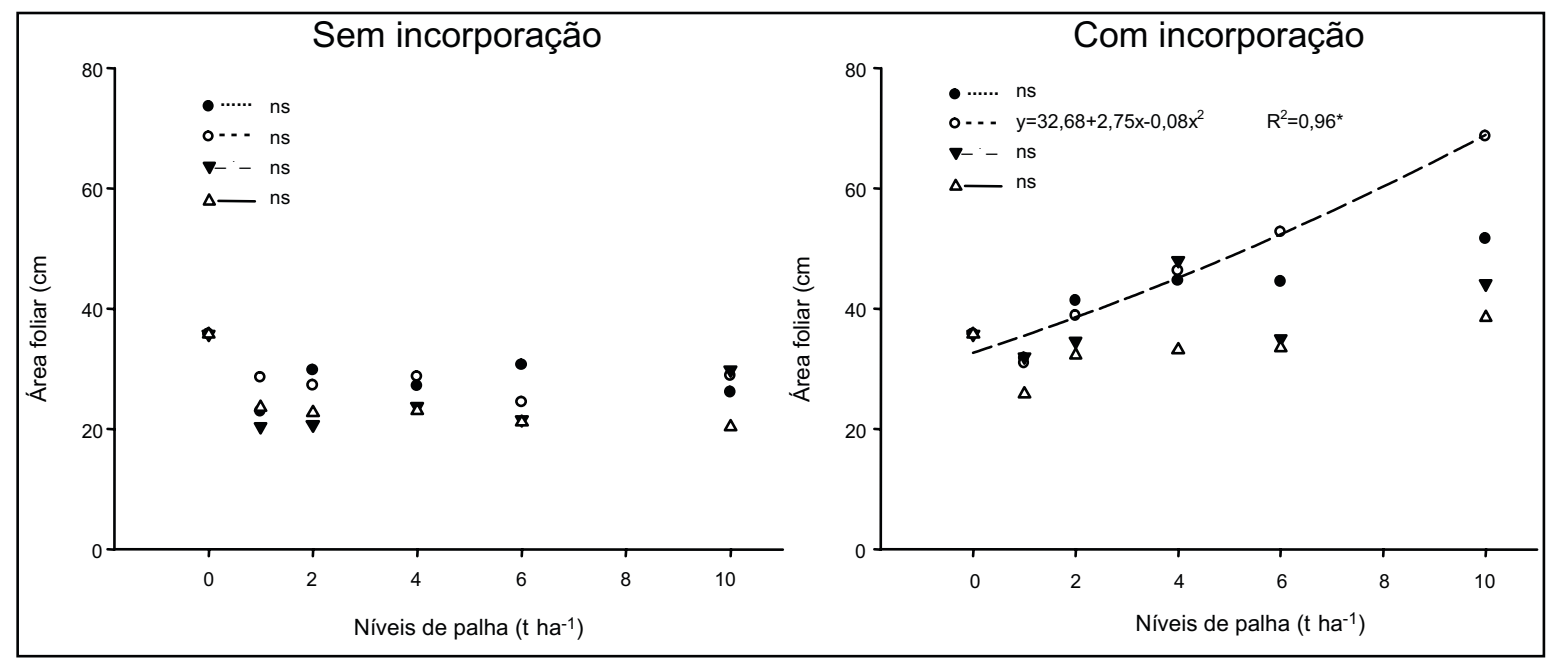

Figura 4 - Efeito de manejo, espécies e níveis de palha de culturas utilizadas como cobertura de solo na área foliar de Digitaria spp. (milhã). ( $\bullet$ canola; o nabo forrageiro; $\boldsymbol{\nabla}$ trevo-vesiculoso; e $\Delta$ azevém). $\mathrm{R}^{2}$ : coeficiente de determinação; ${ }^{\text {ns }} \mathrm{e}^{*}$ não significativo e significativo, respectivamente $(\mathrm{p} \leq 0,05)$.

geral, redução da MSPA de milhã, comparativamente à incorporação ao solo. Do total de comparações realizadas, excluindo as testemunhas, $85 \%$ das comparações diferiram. A cobertura nabo forrageiro e trevo-vesiculoso em todos os niveis de palha na superfície diferiu dos niveis de palha incorporados (Tabela 5).

$\mathrm{O}$ azevém foi a cultura de cobertura que, na superficie do solo ou incorporado, apresentou maior redução na MSPA de milhã, principalmente a partir de 6 e $2 \mathrm{t} \mathrm{ha}^{-1}$ de palha, respectivamente, quando comparado às demais culturas de cobertura (Tabela 5).
Resultados contrários foram verificados por Mathiassen et al. (2006), em que a incorporação de resíduos de trigo ao solo reduz de forma mais efetiva o peso verde de diferentes plantas daninhas, ao contrário do manejo da palha na superficie. Maciel et al. (2003) observaram que a matéria seca de soja foi reduzida quando incorporada palha de capim-braquiária ao solo; o mesmo não foi observado para a planta daninha leiteiro.

Para Monquero et al. (2009), o efeito na redução da massa seca de plantas daninhas pode ser mais dependente da espécie de 
cobertura e planta daninha do que do manejo adotado.

Os niveis de palha das culturas de cobertura, para a variável MSPA de milhã, não demonstraram bom ajuste dos dados ao modelo. Quando os niveis de palha não foram incorporados ao solo, não houve ajuste dos dados ao modelo. Contudo, quando incorporados, ocorreu aumento na MSPA de milhã, conforme aumento dos niveis de palha de nabo forrageiro (Figura 5).

Em estudo com resíduos de nabo forrageiro incorporado ao solo, Norsworthy (2003) verificou que a matéria fresca das plantas daninhas tiririca, mata-pasto e guanxuma e de culturas como milho, algodão e trigo foi reduzida com o aumento da porcentagem de resíduos incorporados ao solo. Os fatores estudados apresentaram interação para a variável matéria seca radicular (MSR) de milhã. As coberturas de solo, quando mantidas na superficie, promoveram de modo geral menor aumento da variável MSR, com exceção do azevém, que mostrou redução da variável, quando comparadas à incorporação ao solo. Do total de comparações realizadas, excluindo as testemunhas, em $80 \%$ das comparações

Tabela 5 - Matéria seca da parte aérea (g) de Digitaria spp. (milhã), em função de manejo, espécies e níveis de palha de culturas utilizadas como cobertura de solo

\begin{tabular}{|c|c|c|c|c|c|c|c|c|}
\hline \multirow{2}{*}{$\begin{array}{c}\text { Nível de } \\
\text { palha } \\
\left(\mathrm{t} \mathrm{ha}^{-1}\right)\end{array}$} & \multicolumn{4}{|c|}{ Sem incorporação } & \multicolumn{4}{|c|}{ Com incorporação } \\
\hline & Canola & $\begin{array}{c}\text { Nabo } \\
\text { forrageiro }\end{array}$ & $\begin{array}{c}\text { Trevo- } \\
\text { vesiculoso }\end{array}$ & Azevém & Canola & $\begin{array}{c}\text { Nabo } \\
\text { forrageiro }\end{array}$ & $\begin{array}{c}\text { Trevo- } \\
\text { vesiculoso }\end{array}$ & Azevém \\
\hline 0 & $0,18 \mathrm{a}^{\mathrm{1}^{/ / \mathrm{ns}}}$ & $0,18 \mathrm{a}^{\mathrm{ns}}$ & $0,18 \mathrm{a}^{\mathrm{ns}}$ & $0,18 a^{\mathrm{ns}}$ & $0,18 \mathrm{a}$ & $0,18 \mathrm{a}$ & $0,18 \mathrm{a}$ & $0,18 \mathrm{a}$ \\
\hline 1 & $0,13 \mathrm{a} *$ & $0,15 \mathrm{a}^{*}$ & $0,11 \mathrm{a} *$ & $0,12 \mathrm{a}^{\mathrm{ns}}$ & $0,18 \mathrm{a}$ & $0,18 \mathrm{a}$ & $0,15 \mathrm{a}$ & $0,14 \mathrm{a}$ \\
\hline 2 & $0,18 \mathrm{a}^{*}$ & $0,15 \mathrm{ab} *$ & $0,12 b c^{*}$ & $0,10 \mathrm{c}^{*}$ & $0,25 \mathrm{a}$ & $0,25 \mathrm{a}$ & $0,20 \mathrm{ab}$ & $0,15 \mathrm{~b}$ \\
\hline 4 & $0,15 \mathrm{a} *$ & $0,15 \mathrm{a} *$ & $0,14 \mathrm{a}^{*}$ & $0,12 \mathrm{a}^{\mathrm{ns}}$ & $0,24 \mathrm{~b}$ & $0,25 \mathrm{~b}$ & $0,32 \mathrm{a}$ & $0,16 \mathrm{c}$ \\
\hline 6 & $0,19 \mathrm{a}^{\mathrm{ns}}$ & $0,16 \mathrm{ab} *$ & $0,14 \mathrm{bc} *$ & $0,11 \mathrm{c} *$ & $0,20 \mathrm{~b}$ & $0,31 \mathrm{a}$ & $0,21 \mathrm{~b}$ & $0,18 \mathrm{~b}$ \\
\hline 10 & $0,16 \mathrm{a}^{*}$ & $0,15 \mathrm{ab} *$ & $0,18 \mathrm{a}^{*}$ & $0,10 b^{*}$ & $0,20 \mathrm{c}$ & $0,36 \mathrm{a}$ & $0,29 \mathrm{~b}$ & $0,17 \mathrm{c}$ \\
\hline
\end{tabular}

${ }^{1}$ Médias seguidas por mesma letra minúscula na linha analisam culturas dentro de manejos da cobertura no solo e não diferem pelo teste de Tukey $(\mathrm{p} \leq 0,05) ;{ }^{\text {ns }} \mathrm{e} *$ diferença não significativa e significativa, respectivamente, pelo teste $\mathrm{t}(\mathrm{p} \leq 0,05)$, para cada cultura entre os manejos.

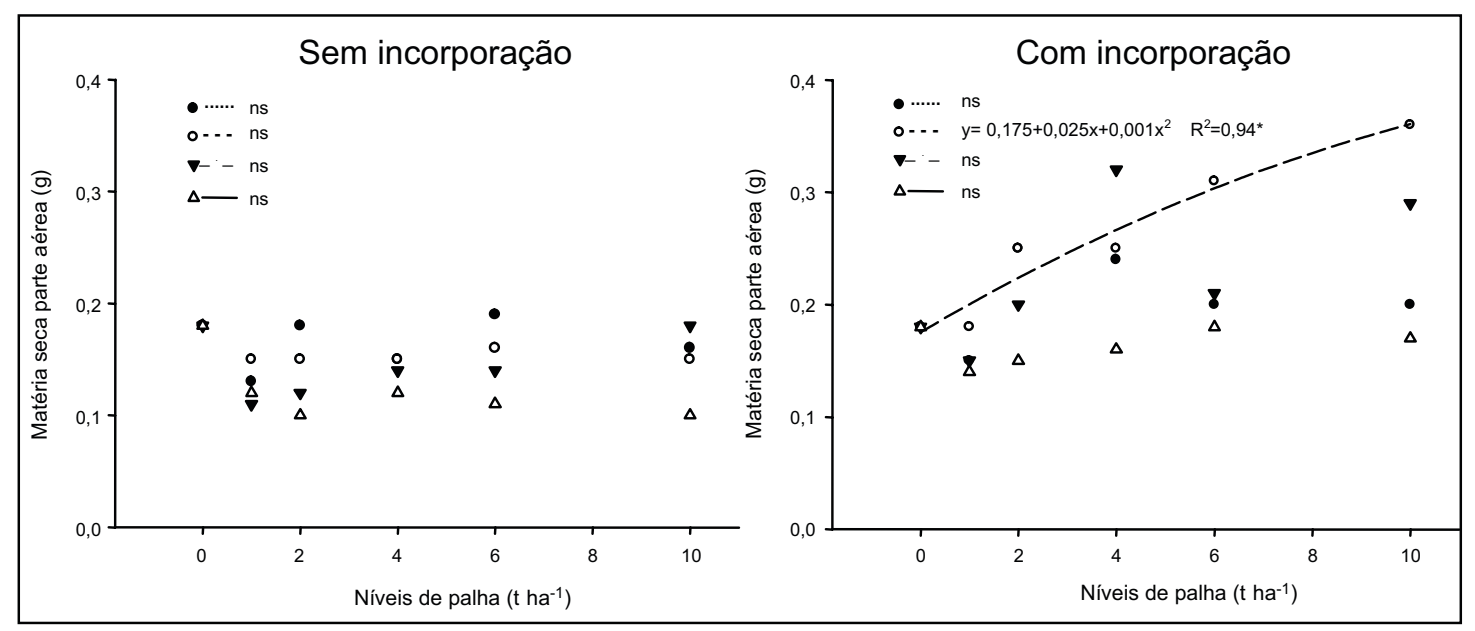

Figura 5 - Efeito de manejo, espécies e níveis de palha de culturas utilizadas como cobertura de solo na matéria seca da parte aérea de Digitaria spp. (milhã). ( • canola; o nabo forrageiro; $\boldsymbol{\nabla}$ trevo-vesiculoso; e $\Delta$ azevém). R ${ }^{2}$ : coeficiente de determinação; ${ }^{\mathrm{ns}} \mathrm{e}^{*}$ não significativo e significativo, respectivamente $(\mathrm{p} \leq 0,05)$. 
verificou-se diferença. Para as culturas de nabo forrageiro e trevo-vesiculoso sem incorporação, houve diferença em todos os níveis, quando comparados à incorporação da palha ao solo (Tabela 6).

Na comparação entre culturas de cobertura dentro de cada manejo da palha, verificouse que a cobertura de azevém mantida na superfície do solo proporcionou maior redução na MSR de milhã a partir de $2 \mathrm{t} \mathrm{ha}^{-1}$ de palha, ao passo que as demais culturas de cobertura proporcionaram aumento da variável, em relação à testemunha. Resultado semelhante foi observado quando realizada a incorporação da palha no solo, onde a palha de azevém reduziu a MSR de plantas de milhã, ao contrário das demais culturas de cobertura (Tabela 6).

As diferentes respostas das palhas sobre a planta daninha podem ser justificadas pela sua constituição química, associada ou não às propriedades alelopáticas, e até mesmo pela geometria do resíduo vegetal, que condicionará uma cobertura mais eficiente do solo (Correia et al., 2006).

Os niveis de palha das culturas de cobertura, para a variável-resposta MSR de milhã, demonstraram ajuste dos dados ao modelo somente para nabo forrageiro quando na

Tabela 6 - Matéria seca radicular (g) de Digitaria spp. (milhã), em função de manejo, espécies e níveis de palha de culturas utilizadas como cobertura de solo

\begin{tabular}{|c|c|c|c|c|c|c|c|c|}
\hline \multirow{2}{*}{$\begin{array}{c}\text { Nível de } \\
\text { palha } \\
\left(\mathrm{t} \mathrm{ha}^{-1}\right)\end{array}$} & \multicolumn{4}{|c|}{ Sem incorporação } & \multicolumn{4}{|c|}{ Com incorporação } \\
\hline & Canola & $\begin{array}{c}\text { Nabo } \\
\text { forrageiro }\end{array}$ & $\begin{array}{c}\text { Trevo- } \\
\text { vesiculoso }\end{array}$ & Azevém & Canola & $\begin{array}{c}\text { Nabo } \\
\text { forrageiro }\end{array}$ & $\begin{array}{c}\text { Trevo- } \\
\text { vesiculoso }\end{array}$ & Azevém \\
\hline 0 & $0,17 \mathrm{a}^{1 / \mathrm{ns}}$ & $0,17 \mathrm{a}^{\mathrm{ns}}$ & $0,17 \mathrm{a}^{\mathrm{ns}}$ & $0,17 \mathrm{a}^{\mathrm{ns}}$ & $0,17 \mathrm{a}$ & $0,17 \mathrm{a}$ & $0,17 \mathrm{a}$ & $0,17 \mathrm{a}$ \\
\hline 1 & $0,13 \mathrm{a} *$ & $0,15 \mathrm{a} *$ & $0,14 \mathrm{a}^{*}$ & $0,12 \mathrm{a}^{\mathrm{ns}}$ & $0,22 \mathrm{a}$ & $0,19 a b$ & $0,19 \mathrm{ab}$ & $0,15 \mathrm{~b}$ \\
\hline 2 & $0,15 \mathrm{ab} *$ & $0,16 \mathrm{a}^{*}$ & $0,14 a b^{*}$ & $0,12 b^{\mathrm{ns}}$ & $0,24 \mathrm{a}$ & $0,22 \mathrm{a}$ & $0,22 \mathrm{a}$ & $0,13 \mathrm{~b}$ \\
\hline 4 & $0,15 \mathrm{ab} *$ & $0,16 a b^{*}$ & $0,18 \mathrm{a}^{*}$ & $0,12 b^{\mathrm{ns}}$ & $0,26 \mathrm{~b}$ & $0,25 \mathrm{~b}$ & $0,31 \mathrm{a}$ & $0,14 \mathrm{c}$ \\
\hline 6 & $0,20 \mathrm{a}^{\mathrm{ns}}$ & $0,15 b^{*}$ & $0,14 b^{*}$ & $0,12 \mathrm{c}^{*}$ & $0,21 \mathrm{~b}$ & $0,31 \mathrm{a}$ & $0,22 \mathrm{~b}$ & $0,19 \mathrm{~b}$ \\
\hline 10 & $0,19 \mathrm{a}^{*}$ & $0,22 \mathrm{a}^{*}$ & $0,19 \mathrm{a}^{*}$ & $0,12 b^{*}$ & $0,23 \mathrm{ab}$ & $0,29 \mathrm{a}$ & $0,30 \mathrm{a}$ & $0,18 \mathrm{c}$ \\
\hline
\end{tabular}

${ }^{1 /}$ Médias seguidas por mesma letra minúscula na linha analisam culturas dentro de manejos da cobertura no solo e não diferem pelo teste de Tukey $(\mathrm{p} \leq 0,05)$; ${ }^{n} \mathrm{e} *$ diferença não significativa e significativa, respectivamente pelo teste $\mathrm{t}(\mathrm{p} \leq 0,05)$, para cada cultura entre os manejos.

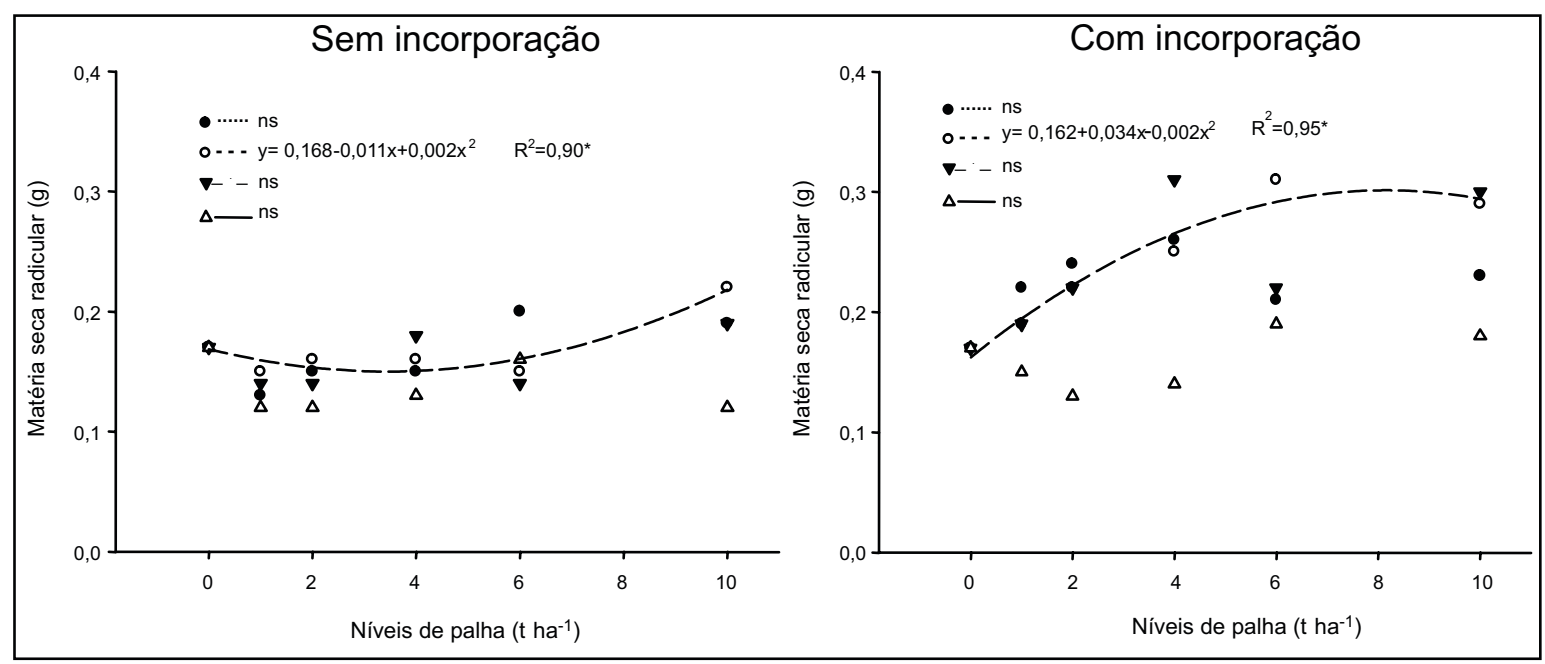

Figura 6 - Efeito de manejo, espécies e níveis de palha de culturas utilizadas como cobertura de solo na matéria seca radicular de Digitaria spp. (milhã). ( $\bullet$ canola; o nabo forrageiro; $\boldsymbol{\nabla}$ trevo-vesiculoso; e $\Delta$ azevém). R ${ }^{2}$ : coeficiente de determinação; ${ }^{\mathrm{ns}} \mathrm{e}^{*}$ não significativo e significativo, respectivamente $(\mathrm{p} \leq 0,05)$. 
superficie ou incorporado ao solo. Para a espécie, os dois manejos proporcionam aumento na MSR de milhã na superfície do solo; o aumento na MSR da planta daninha foi menos acentuado do que quando incorporado ao solo (Figura 6).

Resultados contrários foram verificados por Norsworthy (2003), em que resíduos de nabo forrageiro inibiram severamente raizes de guanxuma e mata-pasto à proporção que aumentou a quantidade de resíduos incorporados ao solo. Assim, com o aumento dos níveis de palha das brássicas incorporadas ao solo, há em geral aumento na redução das variáveis IVE e porcentagem de emergência de milhã. Já a presença da palha de azevém na superfície do solo, de modo geral, reduz o crescimento de milhã, comparativamente à incorporação; para que ocorra redução no crescimento, é necessário ao menos $6 \mathrm{t} \mathrm{ha}^{-1} \mathrm{de}$ palha.

\section{LITERATURA CITADA}

BARBERI, P. et al. Size and composition of the weed seedbank under different management systems for continuous maize cropping. Weed Res., v. 38, n. 5, p. 319-334, 1998.

CORREIA, N. M. et al. Influência do tipo e da quantidade de resíduos vegetais na emergência de plantas daninhas.

Planta Daninha, v. 24, n. 2, p. 245-253, 2006.

EMPRESA BRASILEIRA DE PESQUISA

AGROPECUÁRIA - EMBRAPA. Centro Nacional de Pesquisa Agropecuária de Solos. Sistema brasileiro de classificação de solos. Rio de Janeiro: 2006. 412 p.

FERREIRA, A. G.; ÁQUILA, M. E. A. Alelopatia: uma área emergente da ecofisiologia. R. Bras. Fisiol. Veg., v. 12, n. 1, p. 175-204, 2000.

HARAMOTO, E. R.; GALLANDT, E. R. Brassica cover cropping for weed management: A review. Renew. Agric.

Food Syst., v. 19, n. 4, p. 187-198, 2004.
LÓPEZ-OVEJERO, R. F. et al. Crescimento e competitividade de biótipos de capim-colchão resistente e suscetível aos herbicidas inibidores da acetil coenzima A carboxilase. Pesq. Agropec. Bras., v. 42, n. 1, p. 1-8, 2007

MACIEL, C. D. G. et al. Influência do manejo da palhada de capim-braquiária (Brachiaria decumbens) sobre o desenvolvimento inicial de soja (Glycine max) e leiteiro (Euphorbia heterophylla). Planta Daninha, v. 21, n. 3, p. 365-373, 2003.

MARASCHIN-SILVA, F.; ÁQUILA, M. E. A. Potencial alelopático de espécies nativas na germinação e crescimento inicial de Lactuca sativa L. (Asteraceae). Acta Bot. Bras., v. 20, n. 1, p. 61-69, 2006.

MATHIASSEN, S. K. et al. Herbicidal effects of soilincorporated wheat. J. Agric. Food Chem., v. 54, n. 4, p. $1058-1063,2006$

MEDEIROS, A. R. M.; LUCCHESI, A. A. Efeitos alelopáticos da ervilhaca (Vicia sativa L.) sobre alface em testes de laboratório. Pesq. Agropec. Bras., v. 28, n. 1, p. 9-14, 1993

MONQUERO, P. A. et al. Efeito de adubos verdes na supressão de espécies de plantas daninhas, Planta Daninha, v. 27, n. 1, p. $85-95,2009$.

MORAES, P. V. D. et al. Manejo de plantas de cobertura no controle de plantas daninhas na cultura do milho.

Planta Daninha, v. 27, n. 2, p. 289-296, 2009.

NORSWORTHY, J. K. Allelopathic potencial of wild radish (Raphanus raphanistrum). Weed Technol., v. 17, n. 2, p. 307-313, 2003.

OHNO, T. et al. Phytotoxic effects of red clover amended soils on wild mustard seedling growth. Agric. Ecosyst. Environ., v. 78, n. 2, p. 187-192, 2000.

REZENDE, C. P. et al. Alelopatia e suas interações na formação e manejo de pastagens. B. Agropec., v.2, n. 54, p. $1-55,2003$.

WARDLE, A. D. et al. Allelopathic influence of nodding thistle (Carduns nutans L.) seed on germination and radicle growth of pasture plants. New Zealand J. Agric. Res., v. 34, n. 2, p. 185-191, 1991. 